[Bull. Agr. Chem. Soc. Japan, Vol. 24, No. 7, p. 667 669, 1960]

\title{
Studies on the Constituents of Hemp Plant (Cannabis sativa L.)
}

\author{
Part I. Volatile Phenol Fraction
}

\author{
By Yataro Obata and Yoshinori Ishikawa \\ Department of Agricultural Chemistry, Faculty of Agriculture, Hokkaido-University, Sapporo \\ Received May 30, 1960
}

\begin{abstract}
Examination of the volatile compounds from Japan hemp plant shows that the phenol fraction consists mainly of eugenol with small amounts of guajacol. Two unknown carbonyl compounds are separated as their 2,4-dinitrophenylhydrazones by the silicic acid-celite column chromatography from the phenol fraction.
\end{abstract}

\section{INTRODUCTION}

As the volatile constituents of hemp resin, a terpene b.p. $165 \sim 175^{\circ} \mathrm{C}$, possibly myrcene, and a sesquiterpene were reported by Wood, Spivey, and Easterfield ${ }^{1}$. In 1942, Simonsen and Todd ${ }^{2}$ examined the essential oil from Egyptian hashish of uncertain age, and showed that the "lowerboiling terpene fraction" consists mainly of $p$ cymene with small amounts of 1-methyl-4-isopropenyl-benzene and unidentified optically active material. From the "higher-boiling fraction" of the oil, humulene ( $\alpha$-caryophyllene) was isolated.

In the course of our investigations on hemp plant constituents, the authors examined the volatile phenol fraction and identified eugenol and a trace of guajacol by paper chromatography. After purification of 3,5-dinitrobenzoate derived from the phenol fraction by silicic acidcelite column chromatography, mixed melting points, elemental analysis and infrared spectra proved it as eugenol 3,5-dinitrobenzoate. Eugenol has never been isolated from Moraceae family.

From the aqueous solution of $20 \%$ sodium bisulfite which was used to separate the carbonyls from the crude phenol fraction, two unidentified

1) T. B. Wood, W. T. N. Spivey and T. H. Easterfield, J. Chem. Soc., 69, 539 (1896).

2) J.L. Simonsen and A. R. Todd, J. Chem. Soc., 1942, 188. 2,4-dinitrophenylhydrazones, m.p. $210^{\circ} \mathrm{C}$ and $105 \sim 107^{\circ} \mathrm{C}$ were obtained.

\section{EXPERIMENTAL}

\section{Sample :}

Minamioshihara No. 1 variety of the domestic hemp, raised in the experimental field of Hokkaido University during the season of 1958 was used in this study. It was cut in August just before efflorescence. About 100 $\mathrm{kg}$ of hemp leaves and tops were gathered immediately and extracted with petroleum ether (b.p. $30 \sim 50^{\circ} \mathrm{C}$ ) at the room temperature. Extraction was repeated and the total number of 2101 of petroleum ether was used. Most of the solvent was recovered under $70^{\circ} \mathrm{C}$ of water bath and $22.2 \mathrm{~g}$ of the solids was separated by centrifuge.

The supernatant, about 21 , was shaken with $5 \%$ sodium bicarbonate. After combining the petroleum ether layer with the washings of the precipitate which was formed by the shaking with bicarbonate, 51 of the solution was shaken with aqueous $5 \%$ sodium hydroxide solution. The aqueous extract, acidified with sulfuric acid and saturated with sodium chloride, was shaken with ethyl ether repeatedly and thus crude phenols were obtained. Yield $4.9 \mathrm{~g}$, red oil. The crude phenols were steam-distilled, and the distillate of an amount of 2.51 was saturated with sodium chloride and extracted with ether repeatedly. The volatile phenol fraction, red oil, was obtained from the ether solution. Yield $1.4 \mathrm{~g}$.

Detection of Phenols by Paper Chromatography:

Detetion of phenols in the volatile phenol fraction was carried out by paper chromatography, preparing 
their oxyazocompounds according to the methods of Hossfeld et 2 . $^{3,4)}$. Two drops of the crude phenol fraction was dissolved in $0.1 \mathrm{ml}$ of aqueous $8 \%$ sodium hydroxide. Three drops of diazotized sulfanilic acid were added in this solution. After being acidified with an excess of concentrated hydrochloric acid, the reaction mixture was extracted once with benzene. The aqueous solution was diluted with alcohol and spotted on the position at $4 \mathrm{~cm}$ from the below end of the filter paper which had been sprayed with aqueous $4 \% 6$ sodium carbonate and dried. Water saturated $n$-butanol, a mixture of $n$-butanol add $28 \% \%$ ammonia water ( $4: 1$, $\mathrm{v} / \mathrm{v}$ ) or sec-butanol saturated with aqueous $2 \%$ sodium carbonate were used for irrigating solvent and developed upward at the room temperature. Eugenol and traces of guajacol and few other phenolic compounds were detected in each solvent system.

Isolation and Identification of Eugenol 3,5-Dinitrobenzoate:

The crude phenol fraction was dissolved in $50 \mathrm{ml}$ of ether and shaken with an aqueous solution of $20 \%$ sodium bisulfite to separate the carbonyls. After removal of the carbonyl compounds and being dried, about $1 \mathrm{~g}$ of red oil was dissolved in $3 \mathrm{ml}$ of anhydrous pyridine and $0.5 \mathrm{~g}$ of 3,5-dinitrobenzoyl chloride was added. The mixture was warmed over a low flame for a minute and poured into $10 \mathrm{ml}$ of water. The light brown precipitate was separated and stirred thoroughly with 20 $\mathrm{ml}$ of $2 \%$ sodium bicarbonate solution, and recrystallized from ethyl alcohol. One hundred and sixty $\mathrm{mg}$ of slightly colored needles m.p. $130^{\circ} \mathrm{C}$ was obtained.

The 3,5-dinitrobenzoate was dissolved in a small amount of benzene and added on the top of the column consisting with silicic acid and celite mixed at the rate of $2: 1$ in weight. The column, $10 \mathrm{~cm}$ in its height, was eluted with a mixture of petroleum ether and ethyl ether ( $5 \%$ by volume). Total eluate from the column was $800 \mathrm{ml}$. The solvent was evaporated and the residue was recrystallized from ethyl alcohol. White crystals, $57 \mathrm{mg}$, m.p. $130 \sim 131^{\circ} \mathrm{C}$. An additional crops of $41 \mathrm{mg}$, m.p. $130 \sim 131^{\circ} \mathrm{C}$, was obtained from the filtrate. Anal. Found: C, 57.0; H, 4.0; N, 7.58. Calcd, for $\mathrm{C}_{17} \mathrm{H}_{14}$ $\mathrm{O}_{7} \mathrm{~N}_{2}: \mathrm{C}, 57.0 ; \mathrm{H}, 3.9 ; \mathrm{N}, 7.82$.

The infrared spectrum of this crystal was identical with 3,5-dinitrobenzoate of the authentic eugenol. The mixed melting point of these derivatives did not depress.

\section{Carbonyls is Crude Phenol Fraction:}

3) R. L. Hossfeld, J. Am. Chem. Soc., 73, 852 (1951).

4) Wen-Hua Chang, R. L. Hossfeld and Wm. M. Sandstrom, f. Am. Chem. Soc., 74, 5766 (1952).
The aqueous $20 \%$ sodium bisulfite solution which was used to separate the carbonyls from the volatile phenol fraction was washed with ether, added with $6 \mathrm{~N}$ sulfuric acid and extracted repeatedly with ether. After distilling off the ether, about $400 \mathrm{mg}$ of red oil was obtained. This oil was poured into the solution consisting of $0.5 \mathrm{~g}$ 2,4-dinitrophenylhydrazine, $2 \mathrm{ml}$ concentrated sulfuric acid, $3 \mathrm{ml}$ water and $40 \mathrm{ml}$ ethyl alcohol. After a few days, a separated reddish precipitate of 2,4-dinitrophenylhydrazone, $160 \mathrm{mg}$, was filtered off and dried over $\mathrm{P}_{2} \mathrm{O}_{5}$.

Column Chromatographic Separation of 2,4-dinitrophenylhydrazones:

A mixture of silicic acid and celite, at the rate of $2: 1$ in weight, was added with petroleum ether into a chromatographic glass tube to build a column $(27 \times 250$ $\mathrm{mm}$ ). A chloroform solution of $20 \mathrm{mg} \mathrm{2,4-dinitrophenyl-}$ hydrazones was poured onto the column. After absorption of the chloroform solution, $200 \mathrm{ml}$ of petroleum ether containing ethyl ether (2\%: by volume) was added on the column. As separation of the bands occurred, the ethyl ether content of the mixture solvent was increased to $5 \%$ and $10 \%$ (by volume) and eluted $300 \mathrm{ml}$ and $750 \mathrm{ml}$ respectively. After the first yellow zone (Band No. 1) had been eluted out, 4 bands (No. 2 5) were extruded, sectioned and eluted with ethyl ether. The result obtained with three repetition are shown in Table I.

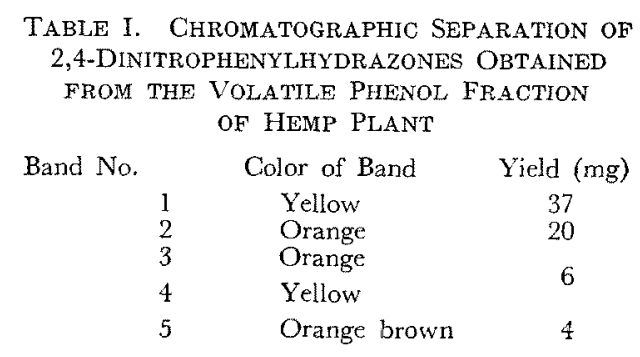

Band No. 1:

Two successive recrystallization from a mixture of petroleum ether and ethyl ether gave yellow crystals, m.p. $105 \sim 107^{\circ} \mathrm{C}, 20 \mathrm{mg}$. The infrared spectrum of this crystal, shown in Fig. 1, was compared with those of authentic 2,4-dinitrophenylhydrazones of $n$-heptylic aldehyde (m.p. $105 \sim 106^{\circ} \mathrm{C}$ ) and $n$-valeric aldehyde (m.p. $107 \sim 108^{\circ} \mathrm{C}$ ), however, did not agree with each one of them.

Band No, 2:

The 2,4-dinitrophenylhydrazone, remained in the flask after removing of the solvent used to elute the orange band (No. 2), was recrystallized from a mixture of ethyl 


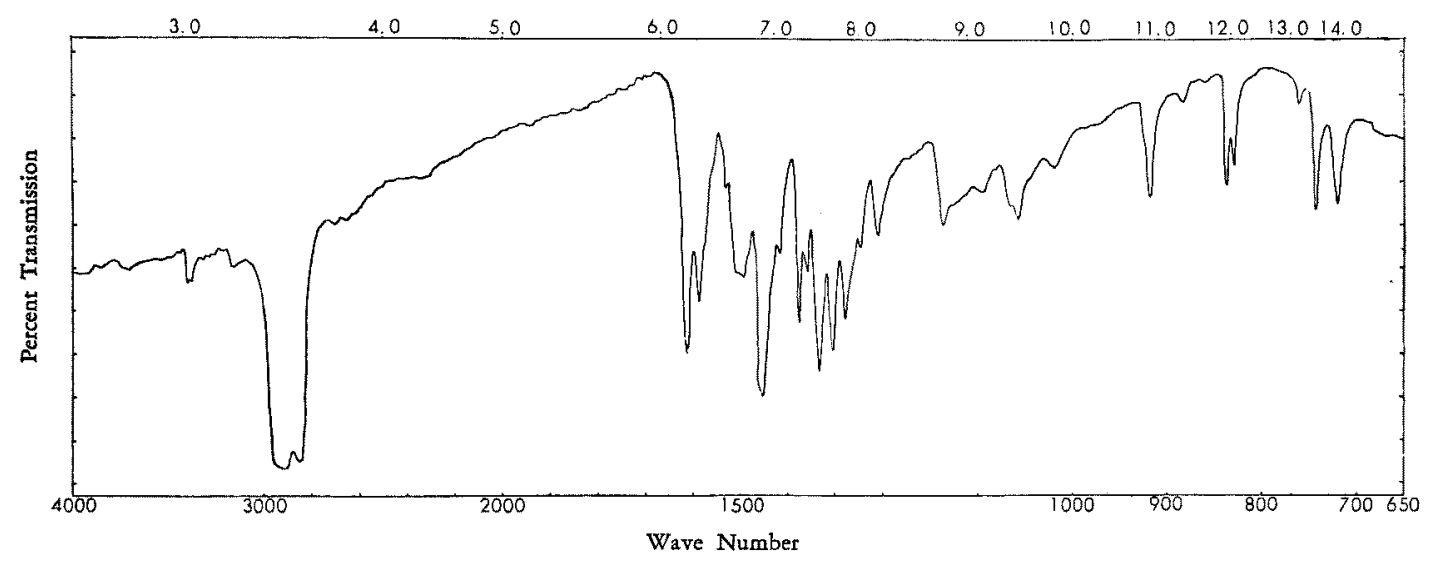

FIG. 1. Infrared Absorption Spectrum of Unknown 2,4-Dinitrophenylhydrazone (m.p. 105 107 ${ }^{\circ} \mathrm{C}$, Band No. 1). Obtained from Hemp Plant (Nujol).

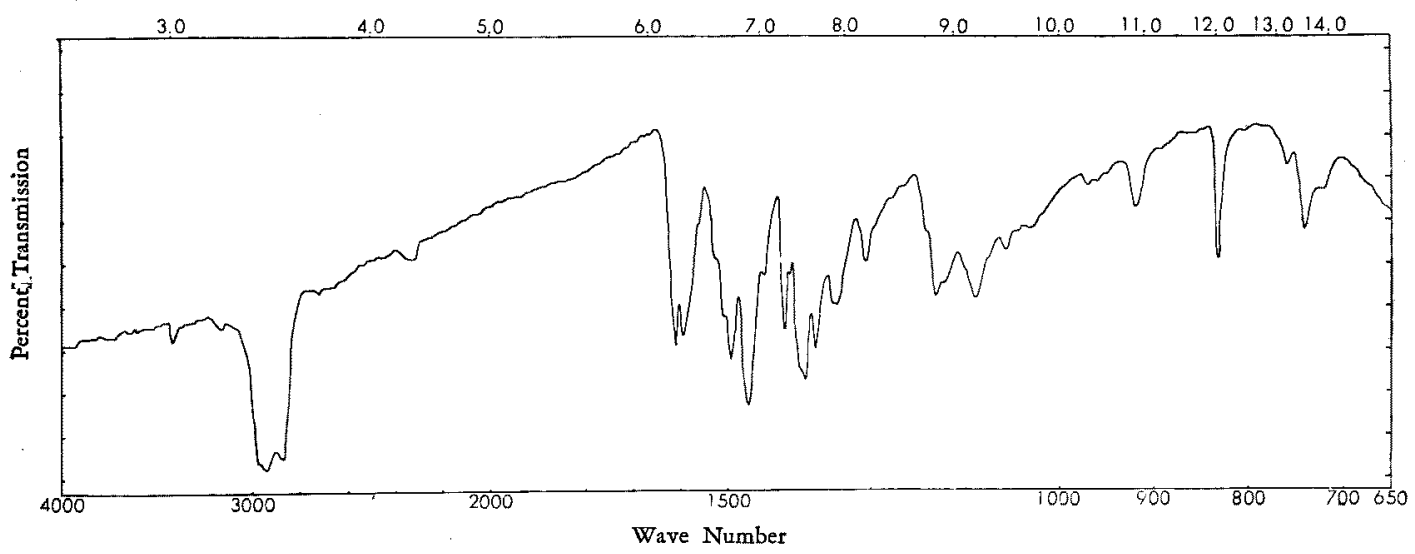

FIG. 2. Infrared Absorption Spectrum of Unknown 2,4-Dinitrophenylhydrazone (m.p. $210^{\circ} \mathrm{C}$, Band No. 2). Obtained from Hemp Plant (Nujol).

ether and chloroform and the melting point was raised to $210^{\circ} \mathrm{C}$. The infrared spectrum of this red crystal, shown in Fig. 2, did not agree with authentic 2,4-dinitrophenylhydrazone of o-hydroxacetophenone (m.p. 210 $213^{\circ} \mathrm{C}$ ) or 5-methyl furfural (m.p. $213 \sim 214^{\circ} \mathrm{C}$ ) prepared from sucrose according to the method of Scott and Johnson ${ }^{5}$.

We could not identify any component of the carbonyls 5) E.W. Scott and J.R. Johnson, J. Am. Chem. Soc., 54, 2549 (1932). because of the lack of sufficient amount for further investigation.

Acknowledgement The authors wish to express their thanks to Mr. K. Narita and Mr. T. Oishi, Department of Pharmacology, Hokkaido Unversity for the microanalysis and the infrared analysis. They are also greatly indebted to $\mathrm{Mr}$. S. Hatae, T. Hasegawa Co., Ltd. for kindly supplying $n$-heptylic aldehyde. 